\title{
Non-malignant chest $x$ ray changes in patients with mesothelioma in a large cohort of asbestos insulation workers
}

\author{
RUTH LILIS, J RIBAK, * Y SUZUKI, LPENNER, NANCY BERNSTEIN, I J SELIKOFF \\ From the Division of Environmental and Occupational Medicine, Department of Community Medicine, Mount \\ Sinai School of Medicine of the City University of New York, New York 10029, USA
}

ABSTRACT To assess the prevalence of non-malignant chest $x$ ray abnormalities in cases of meso thelioma 184 cases of mesothelioma (72 pleural and 112 peritoneal) which had occurred in a cohor: of asbestos insulation workers followed up since 1967 were studied. Chest $x$ ray films of satisfactory quality, on which the presence or absence of non-malignant radiological changes indicating inter?윽 stitial pulmonary fibrosis or pleural fibrosis or both, could be assessed with a high degree of cer= tainty were available. In some cases $(20 \%$ for pleural mesothelioma, $11.6 \%$ for peritoneaE mesothelioma) non-malignant radiological changes were not radiologically detectable. Parenchy mal interstitial fibrosis (small irregular opacities) only was found in a proportion of cases $(25.4 \%$ of pleural mesotheliomas, $12 \cdot 5 \%$ of peritoneal mesotheliomas). Pleural fibrosis only was detected info $17 \%$ of cases of pleural mesothelioma and $27 \%$ of cases of peritoneal mesothelioma. Most patienti had both parenchymal and pleural fibrosis. Although these results tend to indicate that in peritoneaf mesothelioma the proportion of pleural fibrosis is significantly higher, these findings might have been due to the fact that in most cases of pleural mesothelioma non-malignant changes were inter preted in one hemithorax only. In 46 cases ( 21 pleural, 25 peritoneal) in which sufficient lung tissue was available histopathology of lung parenchyma indicated the presence of interstitial fibrosis; in $20 \%$ $(43.5 \%)$ of these the chest $x$ ray film had been read as negative. Thus the absence of radiologically 8 detectable small opacities on the chest $x$ ray film does not exclude the existence of interstitiaE pulmonary fibrosis in cases of mesothelioma among insulation workers. With lower levels of? exposure (such as in family contacts of asbestos workers) it is conceivable that mesothelioma migh occur in the absence of interstitial pulmonary fibrosis.

Mesothelioma, pleural and peritoneal, occurred in 356 members of a large cohort ${ }^{1}$ of asbestos insulation workers. Non-malignant abnormalities on the chest $x$ ray film indicating the presence of interstitial pulmonary fibrosis, pleural fibrosis, and pleural calcifications, preceding the development of the malignant mesothelioma or detectable on the hemithorax opposite to that in which the tumour developed, were of interest, given the widely accepted opinion that mesothelioma can occur after relatively short and low exposure to asbestos ${ }^{2-5}$ (R Lilis et al,

*Present address: Tel-Aviv University, Department of Preventive \& Social Medicine, Sackler School of Medicine, Ramat Aviv, Tel-Aviv, Israel.

Accepted 27 August 1986
VI International Pneumoconiosis Conference, Bochum, May 1983, abstracts pp16, 30).

POPULATION AND METHODS

Mesothelioma had occurred in 356 members of के large cohort of 17800 insulation workers in the United States and Canada, established in 1967. ${ }^{16}$ The diagnosis of malignant mesothelioma was ascertained by thorough review of pathology in all cases by one of us (YS).

In 184 cases chest $x$ ray films of satisfactory qualit $y_{\text {है }}^{\frac{0}{6}}$ were available for review: 112 cases of peritonea! mesothelioma and 72 of pleural mesothelioma. The chest $x$ ray films were interpreted for non-malignanț abnormalities of the lung parenchyma, or of the pleura, by following the criteria of the Internationa范 402 
Table 1 Peritoneal mesothelioma $(n=112)$

$\left.\begin{array}{lcc} & \text { No } & \% \\ \hline \text { Presence of non-malignant pulmonary and pleural } & \text { abnormalities } \\ \text { None } & 13 & 11 \cdot 6 \\ \text { Parenchymal interstitial fibrosis } & & 12 \cdot 5 \\ \text { only (small irregular opacities) } & 14 & 26 \cdot 8 \\ \text { Pleural fibrosis only } & 30 & 49 \cdot 1 \\ \text { Parenchymal and pleural fibrosis } & 55 & \\ & & \\ \text { Parenchymal interstitial fibrosis (irregular opacities) } & \\ \text { Profusion } & & 38 \cdot 4 \\ 0 / 0-0 / 1 & 43 & 40 \cdot 2 \\ \text { 1/0-1/2 } & 45 & 17 \cdot 8 \\ 2 / 1-2 / 3 & 20 & 3.6\end{array}\right\} 61.6 \%$

Classification of Radiographs of Pneumoconioses. ${ }^{7}$

In the 112 cases of peritoneal mesothelioma the full chest $x$ ray film was interpreted for non-malignant abnormalities (parenchymal or pleural, or both). In most of the 72 cases of pleural mesothelioma the interpretation of non-malignant radiological pleuropulmonary changes were made on the hemithorax contralateral to that in which the tumour had developed (60 cases); in 12 cases full chest $x$ ray films preceding the mesothelioma by a relatively short period (several years) were available and were used for interpretation.

Findings in the 112 cases of peritoneal mesothelioma were compared with those in the 72 cases of pleural mesothelioma.

\section{Results}

\section{PERITONEAL MESOTHELIOMA}

Radiological changes indicating the presence of interstitial pulmonary fibrosis (small irregular or rounded opacities, or both) or pleural fibrosis were absent in $13(11.6 \%)$ of the 112 cases of peritoneal mesothelioma. Pleural fibrosis was present in one or more locations in $76.0 \%$ of all cases: chest wall, tangential, or face on, or both, and diaphragmatic plaques.

In $30(26.9 \%)$ cases changes consistent with pleural fibrosis were the only abnormalities detected, whereas in $55(49 \cdot 1 \%)$ small irregular opacities indicating the presence of interstitial fibrosis were associated with pleural fibrosis (table 1).

Small, mostly irregular but sometimes also rounded opacities were radiologically detectable in 69 $(61.6 \%)$ cases; the majority, almost two thirds, showed opacities of type s (according to the ILO classification), and in one third of cases the predominant shape and size of radiologically detectable small opacities was $t$. The profusion of radiologically detectable small opacities was $1 / 0-1 / 2$ in 45 cases (40.2\%), $2 / 1-2 / 3$ in 20 cases $(17 \cdot 8 \%)$, and reached a 3 grading (3/2-3/3) in only four cases (table 1$)$.

Tangential pleural fibrosis was found with similar prevalence on the right in $44(39.4 \%)$ and on the left in $50(44.6 \%)$ cases. The extent and width of tangential pleural fibrosis were also similar. Pleural fibrosis face on was a relatively frequent finding, present in one third of all cases affecting the left hemithorax (in cases of right pleural mesothelioma). The extent $(1,2$, or 3$)$ of pleural fibrosis face on was relatively evenly distributed; for tangential pleural fibrosis, extents 1 and 2 were more prevalent than extent 3, and widths $\mathrm{A}$ and $\mathrm{B}$ were more prevalent than width $\mathrm{C}$ (table 2 ).

Circumscribed pleural fibrosis was found roughly twice as often as diffuse pleural fibrosis (table 3).

Diaphragmatic plaques (table 4) were observed with a similar frequency on the right and on the left hemidiaphragms, in almost half of cases (47.3\% right diaphragmatic plaques and $49.1 \%$ left). They were radiologically non-detectable in $39(34.9 \%)$ cases, bilateral in 35 , present on the left only in 20 , and on the right only in 18 . The costophrenic angle was blunted in less than $20 \%$ of cases, both on the right and on the left hemithorax (table 4). Pleural

Table 2 Peritoneal mesothelioma: tangential pleural fibrosis (in profile) and face on $(\boldsymbol{n}=112)$

\begin{tabular}{|c|c|c|c|c|c|c|c|c|c|}
\hline Pleural fibrosis (tangential) & Right & & Left & & Pleural fibrosis (face on) & Right & & Left & \\
\hline & No & $\%$ & No & $\%$ & & No & $\%$ & No & $\%$ \\
\hline $\begin{array}{l}\text { None } \\
\text { Present }\end{array}$ & $\begin{array}{l}68 \\
44\end{array}$ & $\begin{array}{l}60.7 \\
(39.4)^{*}\end{array}$ & $\begin{array}{l}62 \\
50\end{array}$ & $\begin{array}{l}55 \cdot 3 \\
(44 \cdot 6)^{*}\end{array}$ & $\begin{array}{l}\text { None } \\
\text { Present }\end{array}$ & $\begin{array}{l}83 \\
29\end{array}$ & $\begin{array}{c}74 \cdot 1 \\
(25 \cdot 9)^{*}\end{array}$ & $\begin{array}{l}74 \\
38\end{array}$ & $\begin{array}{c}66 \cdot 1 \\
(33.9)^{*}\end{array}$ \\
\hline $\begin{array}{r}\text { Extent } 1 \\
2 \\
3\end{array}$ & $\begin{array}{r}17 \\
23 \\
4\end{array}$ & $\begin{array}{r}15 \cdot 2 \\
20.5 \\
3.6\end{array}$ & $\begin{array}{r}20 \\
24 \\
6\end{array}$ & $\begin{array}{r}17 \cdot 9 \\
21 \cdot 4 \\
5 \cdot 3\end{array}$ & $\begin{array}{r}\text { Extent } 1 \\
2 \\
3\end{array}$ & $\begin{array}{r}10 \\
11 \\
8\end{array}$ & $\begin{array}{l}8 \cdot 9 \\
9 \cdot 8 \\
7 \cdot 1\end{array}$ & $\begin{array}{l}12 \\
12 \\
14\end{array}$ & $\begin{array}{l}10 \cdot 7 \\
10 \cdot 7 \\
12 \cdot 5\end{array}$ \\
\hline $\begin{array}{r}\text { Width A } \\
\text { B } \\
\text { C }\end{array}$ & $\begin{array}{r}20 \\
18 \\
6\end{array}$ & $\begin{array}{r}17 \cdot 9 \\
16 \cdot 1 \\
5 \cdot 4\end{array}$ & $\begin{array}{r}22 \\
22 \\
6\end{array}$ & $\begin{array}{r}19 \cdot 6 \\
19 \cdot 6 \\
5.4\end{array}$ & & & & & \\
\hline
\end{tabular}

*No $(\%)$ out of 112 cases of peritoneal mesothelioma. 
404

Table 3 Peritoneal mesothelioma $(n=112)$

Pleural fibrosis*

\begin{tabular}{|c|c|c|c|c|c|c|}
\hline \multicolumn{3}{|l|}{ Right } & \multicolumn{4}{|c|}{ Left } \\
\hline $\begin{array}{l}\text { Circumscribed } \\
\text { No } \%\end{array}$ & $\begin{array}{l}\text { Diffuse } \\
\text { No }\end{array}$ & $\%$ & $\begin{array}{l}\text { Circ } \\
\text { No }\end{array}$ & $\underset{\%}{c r i b e d}$ & $\begin{array}{l}\text { Diffuse } \\
\text { No }\end{array}$ & $\%$ \\
\hline $28 \cdot 6$ & 13 & $11 \cdot 6$ & 35 & $31 \cdot 2$ & 20 & 17.9 \\
\hline
\end{tabular}

*Includes pleura face on.

calcifications were not radiologically detected in 67 cases $(59.8 \%)$; they were bilaterally present in 27 $(24 \cdot 1 \%)$ and in more cases, $14(12 \cdot 5 \%)$ on the left than on the right, four $(3.6 \%)$.

\section{PLEURAL MESOTHELIOMA}

Seventy two cases of pleural mesothelioma had chest $x$ ray films satisfactory for interpreting nonmalignant pleural and parenchymal changes, either on the hemithorax opposite to the tumour (in 60 cases) or on the full chest $x$ ray film that had preceded the development of mesothelioma by several years. The malignant mesothelioma had developed on the right side in $43(59.7 \%)$ cases and on the left in 27 $(37.5 \%)$; in two cases the primary site remained unidentified (table 5). The contralateral site was interpreted in 35 cases of right pleural mesothelioma and in 25 cases of left mesothelioma, whereas the full chest $x$ ray film was read in eight cases of right and two of left mesothelioma (table 5).

In 14 cases $(19.7 \%)$ there was absence of radiologically detectable non-malignant abnormalities (table 6). Parenchymal changes only (small irregular or rounded opacities) were found in $18(25.4 \%)$ cases, a higher proportion than that of cases with peritoneal mesothelioma $(12.5 \%)$. Pleural fibrosis only was present in $12(16.9 \%)$ cases of pleural mesothelioma, whereas an association between parenchymal and pleural fibrosis was the most frequent occurrence in $27(38 \%)$ cases.

Small parenchymal opacities, mostly irregular but

Table 4 Peritoneal mesothelioma

\begin{tabular}{lrr}
\hline & No & $\%$ \\
\hline Diaphragmatic pleural plaques: & & \\
None & 39 & 34.8 \\
Bilateral & 35 & 31.2 \\
Left & 20 & 17.9 \\
Right & 18 & 16.1 \\
& 112 & 100.0 \\
Costophrenic angle blunted: & & \\
$\quad$ Right & 21 & 18.7 \\
Left & 22 & 19.6 \\
\hline
\end{tabular}

Lilis, Ribak, Suzuki, Penner, Bernstein, and Selikof店

Table 5 Pleural mesothelioma $(n=72)$

\begin{tabular}{|c|c|c|}
\hline $\begin{array}{l}\text { Location of tumour } \\
\text { Hemithorax }\end{array}$ & No & $\%$ \\
\hline $\begin{array}{l}\text { Right } \\
\text { Left } \\
\text { Side unindentified }\end{array}$ & $\begin{array}{r}43 \\
27 \\
2\end{array}$ & $\begin{array}{r}59 \cdot 7 \\
37 \cdot 5 \\
2 \cdot 8\end{array}$ \\
\hline \multicolumn{3}{|c|}{$\begin{array}{l}\text { Interpretation of chest } x \text { ray films of pleural mesothelioma for } \\
\text { non-malignant pulmonary and pleural abnormalities }\end{array}$} \\
\hline Contralateral & $\begin{array}{l}\text { Right pleural } \\
\text { mesothelioma }\end{array}$ & $\begin{array}{l}\text { Left pleural } \\
\text { mesothelioma }\end{array}$ \\
\hline $\begin{array}{l}\text { Full chest } x \text { ray film (preceding } \\
\text { malignant mesothelioma) }\end{array}$ & 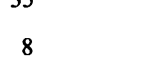 & 25 \\
\hline
\end{tabular}

also rounded, indicating interstitial pulmonary fibrosis, were detected in $45(62.5 \%)$ cases with pleu ral mesothelioma. The profusion of small opacities was $1 / 0-1 / 2$ in $35(48.6 \%)$ and $2 / 1-2 / 3$ in $10(13.9 \%$ g cases. As with peritoneal mesothelioma, the predom $=$ inant type of small irregular opacities was $s$ (in $62.7 \%$ of cases) followed by $t$ in 21 (35.6\% of cases).

The prevalence of tangential fibrosis (tables 7 and 8) approached $50 \%$ for both the right and left hemi thorax (somewhat higher than in peritoneal meso- thelioma). Diffuse pleural fibrosis was much less frequent ( $25 \%$ of all cases of pleural fibrosis) than circumscribed pleural fibrosis (table 9). Pleurap fibrosis face on was again found relatively often in $1 \%$ $(22 \cdot 2 \%)$ cases. Pleural diaphragmatic plaques wer found with a much lower prevalence $(45.8 \%)$ than in the cases of peritoneal mesothelioma where it was $65 \cdot 2 \%$. There is a strong possibility that the unilateraf chest $x$ ray film interpretation for non-malignan radiological changes had a significant influence on this lower prevalence of diaphragmatic plaquesD detected in pleural as compared with peritoneal meso thelioma. Blunting of the costophrenic angle was found with similar frequency ( $18 \cdot 1 \%$ of cases).

Pleural calcifications were found with a highes

Table 6 Pleural mesothelioma $(n=72)$

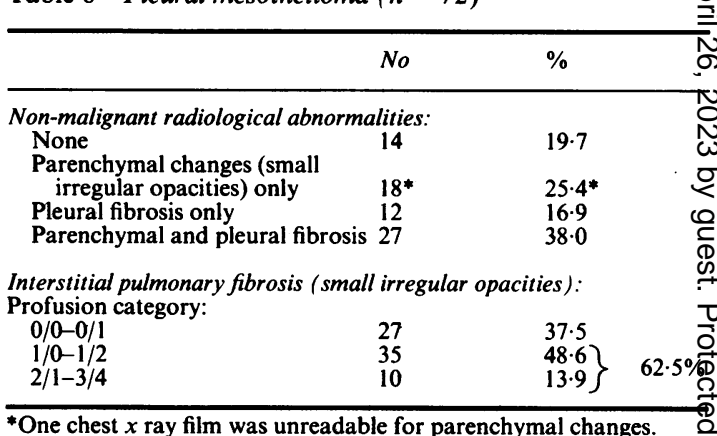

*One chest $x$ ray film was unreadable for parenchymal changes. 
Table 7 Pleural mesothelioma $(n=72)$

Chest $x$ ray interpretations for pleural abnormalities

\begin{tabular}{|c|c|c|c|c|c|}
\hline & \multirow{2}{*}{$\begin{array}{l}\text { Right } \\
\text { hemithorax } \\
\text { (left tumour) } \\
(n=25)\end{array}$} & \multirow{2}{*}{$\begin{array}{l}\text { Left } \\
\text { hemithorax } \\
\text { (right tumour) } \\
(n=35)\end{array}$} & \multirow{2}{*}{$\begin{array}{l}\text { Total chest } \\
\text { x ray (preceding } \\
\text { tumour) } \\
(n=12)\end{array}$} & \multicolumn{2}{|c|}{ Total } \\
\hline & & & & No & $\%$ \\
\hline $\begin{array}{l}\text { Pleural fibrosis (tangential) } \\
\text { Pleural fibrosis face on } \\
\text { Pleural diaphragmatic }\end{array}$ & $\begin{array}{l}8 \\
3\end{array}$ & $\begin{array}{l}17 \\
11\end{array}$ & $\begin{array}{l}7(3)^{*} \\
2(2)^{*}\end{array}$ & $\begin{array}{l}32 \\
16\end{array}$ & $\begin{array}{l}(44 \cdot 4) \\
(22 \cdot 2)\end{array}$ \\
\hline $\begin{array}{l}\text { plaques } \\
\text { Costophrenic angle }\end{array}$ & $\begin{array}{r}10 \\
5\end{array}$ & $\begin{array}{r}15 \\
3\end{array}$ & $\begin{array}{l}8(5)^{*} \\
5(1)^{*}\end{array}$ & $\begin{array}{l}33 \\
13\end{array}$ & $\begin{array}{l}(45 \cdot 8) \\
(18 \cdot 1)\end{array}$ \\
\hline
\end{tabular}

*Bilateral pleural fibrosis present.

prevalence $(20 \%)$ on the right hemithorax (in the case of left mesothelioma) and on the left (34.3\%) hemithorax (in the case of right mesothelioma) than was the case with peritoneal mesothelioma, where the corresponding prevalences were 3.6 and $12.5 \%$. There were, nevertheless, an additional $24 \cdot 1 \%$ of cases of peritoneal mesothelioma with bilateral pleural calcifications.

In 46 of the 184 cases ( 21 pleural, 25 peritoneal) lung tissue was available for histopathology assessment of interstitial fibrosis. Whereas in $20(43.5 \%)$ of the 46 the radiological interpretation was negative

Table 8 Pleural mesothelioma $(n=72)$

\begin{tabular}{rll}
\hline Pleural fibrosis: tangential & \multicolumn{2}{l}{ Right } \\
& No & $\begin{array}{l}\text { Left } \\
\text { No }\end{array}$ \\
\hline Extent 1 & $5(2)^{*}$ & $6(1)^{*}$ \\
2 & $7(3)^{*}$ & $13(1)^{*}$ \\
3 & $1(0)^{*}$ & $3(3)^{*}$ \\
Width A & $6(2)^{*}$ & $7(2)^{*}$ \\
B & $4(3)^{*}$ & $12(2)^{*}$ \\
C & $3(0)^{*}$ & $3(1)^{*}$ \\
Total & 13 & 22 \\
\hline
\end{tabular}

*Cases in which full chest $x$ ray films preceding the malignant pleural mesothelioma were available (total number $=12$ ). (small opacities $0 / 0$ in $8,0 / 1$ in 12 cases), histopathological evidence of interstitial fibrosis was present in all.

\section{Discussion and conclusions}

The relations between both pleural fibrosis and radiologically detectable interstitial fibrosis with the type of mesothelioma - pleural or peritoneal - were tested by using chi-square statistics. Pleural changes were found in $76 \%$ of the cases of peritoneal mesothelioma and in only $55 \%$ of cases of pleural mesothelioma $\left(\chi^{2}=8.74 ; p=0.003\right)$. Therefore, there seemed to be an association between type of mesothelioma and pleural fibrosis, with cases of peritoneal mesothelioma having a greater frequency of pleural changes. Nevertheless, this apparent higher prevalence of pleural fibrosis among the cases of peritoneal mesothelioma might be, at least in part, due to the fact that in most cases of pleural mesothelioma nonmalignant changes were interpreted in one hemithorax only. With regard to parenchymal changes, no association with type of mesothelioma, peritoneal or pleural, was found $\left(\chi^{2}=0.058 ; p=n s\right)$.

As was shown by the comparison of radiological parenchymal abnormalities and histopathological changes, the absence of radiologically detectable small opacities on the chest $x$ ray film does not exclude the existence of interstitial pulmonary fibrosis in cases of mesothelioma among insulation workers.

Table 9 Pleural mesothelioma $(n=72)$

Pleural fibrosis: circumscribed and diffuse

\begin{tabular}{lllll}
\hline & $\begin{array}{l}\text { Right } \\
\text { hemithorax } \\
(\text { left tumour }) \\
(n=25)\end{array}$ & $\begin{array}{l}\text { Left } \\
\text { hemithorax } \\
\text { (right tumour }) \\
(n=35)\end{array}$ & $\begin{array}{l}\text { Total chest } \\
\text { x ray (preceding } \\
\text { tumour) } \\
(n=12)\end{array}$ & Total No \\
\hline $\begin{array}{l}\text { Pleural fibrosis } \\
\text { circumscribed }\end{array}$ & 6 & 15 & $6(1)^{*}$ & 27 \\
\begin{tabular}{l} 
Pleural fibrosis diffuse \\
\hline
\end{tabular} & 3 & 2 & $4(0)^{*}$ & 9 \\
\hline
\end{tabular}

*Bilateral pleural fibrosis was present. 
406

Similar findings have recently been reported in cases of lung cancer from the same cohort. ${ }^{8}$

The possibility still exists that mesothelioma due to past exposure to asbestos might occur in the absence of interstitial pulmonary fibrosis in subjects with lower levels of asbestos exposure than that which characterised insulation work in the past. The findings in this study of cases of mesothelioma from the cohort of asbestos insulation workers cannot be extrapolated to lower levels of exposure that are known to have resulted in cases of mesothelioma among, for example, family contacts of workers exposed to asbestos. ${ }^{9}$

\section{References}

1 Selikoff IJ, Hammond EC, Seidman H. Mortality experience of insulation workers in the United States and Canada,
Lilis, Ribak, Suzuki, Penner, Bernstein, and Selikoff

1943-1976. Annals NY Acad Sci 1979;330:91-116.

2 Anderson HA, Lilis R, Daum SM, Selikoff IJ. Asbestosis amongू household contacts of asbestos factory workers. Annals $N Y_{\rightarrow}$. Acad Sci 1979;330:387-400.

3 Vianna NJ, Polan AK. Non-occupational asbestos exposure and malignant mesotheliomas in females. Lancet 1978;i:1061-3. T

4 Newhouse ML, Thompson H. Mesothelioma of pleura and peritoneum following exposure to asbestos in the London Area. Bris $J$ Ind Med 1965;22:261-9.

5 Newhouse ML. Asbestos in the workplace and the community Ann Occup Hyg 1973;16:97-102.

6 Ribak J, Lilis R, Suzuki Y, Penner L, Selikoff IJ. Malignant mesothelioma-clinical characteristics. Br J Ind Med (in press) $\overrightarrow{0}$

7 International Labour Office. Guidelines for use of ILO International Classification of Radiographs of Pneumoconioses. Rev $\vec{w}$ 80. Geneva; ILO, 1980. (Occupational Safety Health Series Nog 22.)

8 Kipen HM, Lilis R, Suzuki Y, Valciukas JA, Selikoff IJ. Radio- $-\frac{\Phi}{3}$ logic and histopathologic evaluation of pulmonary fibrosis irf asbestos insulation workers with lung cancer. Br J Ind Med (in press).

के

9 Anderson HA, Lilis R, Daum SM, Fischbein AS, Selikoff IJ:A Household contact asbestos neoplastic risk. Annals NY Acad Sci 1976;271:311-23.

\section{Correspondence and editorials}

The British Journal of Industrial Medicine welcomes correspondence relating to any of the material appearing in the journal. Results from preliminary or small scale studies may also be published in the correspondence column if this seems appropriate. Letters should be not more than 500 words in length and contain a minimum of references. Tables and figures should be kept to an absolute minimum. Letters are accepted on the understanding that they may be subject to editorial revision and shortening.

The journal now also publishes editorials which are normally specially commissioned. The Editor welcomes suggestions regarding suitable topics; those wishing to submit an editorial, however, should do so only after discussion with the Editor. 